\title{
Estimation of slip parameters associated with frictional heating during the 1999 Taiwan Chi-Chi earthquake by vitrinite reflectance geothermometry
}

Yuka Maekawa ${ }^{1}$, Tetsuro Hirono ${ }^{1 *}$, Hikaru Yabuta ${ }^{1}$, Hideki Mukoyoshi $^{2}$, Manami Kitamura ${ }^{3}$, Minoru Ikehara ${ }^{4}$, Wataru Tanikawa ${ }^{5}$ and Tsuyoshi Ishikawa ${ }^{5}$

\begin{abstract}
To estimate the slip parameters and understand the fault lubrication mechanism during the 1999 Taiwan Chi-Chi earthquake, we applied vitrinite reflectance geothermometry to samples retrieved from the Chelungpu fault. We found a marked reflectance anomaly of $1.30 \% \pm 0.21 \%$ in the primary slip zone of the earthquake, whereas the reflectances in the surrounding deformed and host rocks were $0.45 \%$ to $0.77 \%$. By applying a kinetic model of vitrinite thermal maturation together with a one-dimensional heat and thermal diffusion equation, we determined the shear stress and peak temperature in the slip zone during the earthquake to be $1.00 \pm 0.04 \mathrm{MPa}$ and $626^{\circ} \mathrm{C} \pm 25^{\circ} \mathrm{C}$, respectively. Taking into account the probable overestimation of the temperature owing to a mechanochemically enhanced reaction or flash heating at grain contacts, this temperature should be considered an upper limit. The lower limit was previously constrained to $400^{\circ} \mathrm{C}$ by studies of fluid-mobile trace-element concentrations and magnetic minerals. Therefore, we inferred that the peak temperature during the Chi-Chi earthquake was $400^{\circ} \mathrm{C}$ to $626^{\circ} \mathrm{C}$, corresponding to an apparent friction coefficient of 0.01 to 0.06 . Such low friction and the previous evidence of a high-temperature fluid suggest that thermal pressurization likely contributed to dynamic weakening during the Chi-Chi earthquake.
\end{abstract}

Keywords: Carbonaceous material; Thermal maturation; Fault friction; Chelungpu fault

\section{Findings} Introduction

The 1999 Taiwan Chi-Chi earthquake ( $\left.M_{w} 7.6\right)$ exhibited spatially heterogeneous slip behavior. The largest ground velocity and displacement (up to $3 \mathrm{~m} \cdot \mathrm{s}^{-1}$ and $8 \mathrm{~m}$, respectively) were recorded at the northern end of the Chelungpu fault, whereas the level of high-frequency radiation was lower at the northern end rather than at the southern end (Shin and Teng 2001). Ma et al. (2003) attributed the seismological characteristics to a slip mechanism involving elastohydrodynamic lubrication, inferring that increased pressure of viscous gouge widened the gap between the fault surfaces, thereby reducing the contact

\footnotetext{
* Correspondence: hirono@ess.sci.osaka-u.ac.jp

'Department of Earth and Space Science, Graduate School of Science, Osaka University, Toyonaka, Japan

Full list of author information is available at the end of the article
}

areas of asperities and decreasing the levels of highfrequency radiation and friction. Andrews (2005) proposed a thermal pressurization mechanism, in which fluid pressure generated by shear-related heating reduced the fault strength during seismic slip.

To investigate the dynamic fault weakening mechanism associated with the Chi-Chi earthquake, the Taiwan Chelungpu-fault Drilling Project (TCDP), started in 2002, penetrated the Chelungpu fault (Figure 1) and recovered core samples from two holes, Hole A (total depth 2,003.00 m) and Hole B (total depth 1,352.60 m). In Hole B core samples, three dominant fault zones, FZB1136 (fault zone around 1,136 m depth in Hole B), FZB1194, and FZB1243, were observed within the Chinshui shale (Figure 1) and interpreted as segments of the Chelungpu fault (Hirono et al. 2006, 2007a, 2008). The shallowest fault zone was

\section{Springer}




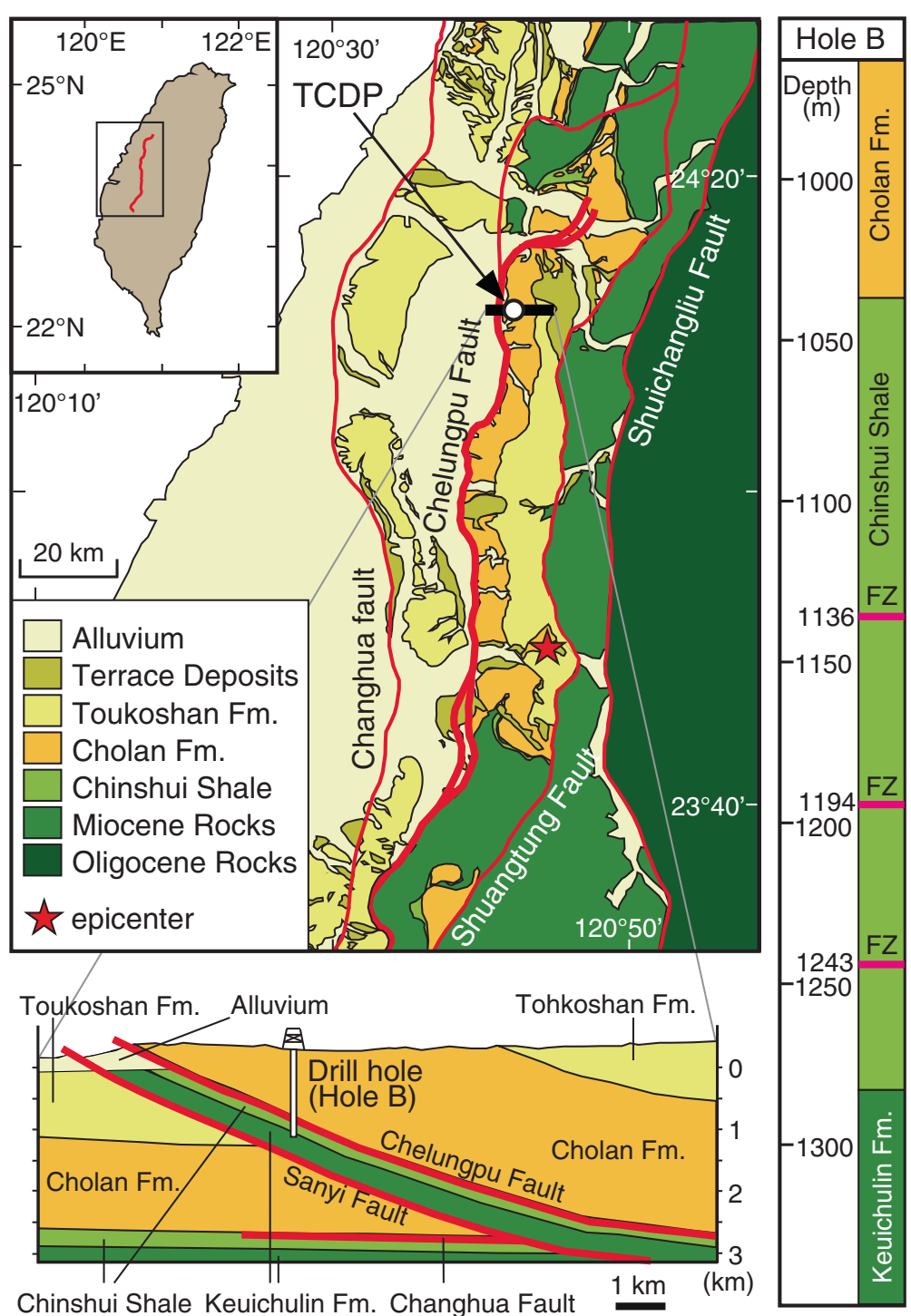

Figure 1 Geological map of central Taiwan, an E-W cross section through site, and three dominant fault zones discovered. The map shows the site of Taiwan Chelungpu-fault Drilling Project (TCDP). Dominant fault zones have depths 1,136. 1,194, and $1243 \mathrm{~m}$ in the Hole B core, which correspond to the fault zones at depths 1,111, 1,153, 1,221 $\mathrm{m}$ in the Hole A core, respectively (Hirono et al. 2007a).

most likely the one that slipped during the Chi-Chi earthquake because recent heating and a major stress-orientation anomaly were observed in that zone (Kano et al. 2006; Wu et al. 2007; Lin et al. 2007).

Determination of the peak temperature during slip is crucial to identify the faulting mechanism during an earthquake, because thermal pressurization (as well as melt lubrication) is promoted by frictional heating on the fault. Comprehensive mineralogical, geochemical, and magnetic analyses of Hole B core samples have been performed, and some temperature information during the Chi-Chi earthquake has been obtained. Ikehara et al. (2007) reported that the inorganic carbon content of the fault gouge was low, and attributed the low value to thermal decomposition of carbonate minerals. A chemical kinetic evaluation based on the Arrhenius equation of the thermal decomposition reaction induced by earthquake slip estimated the temperature reached in response to frictional heating during the Chi-Chi earthquake to be $868^{\circ} \mathrm{C}$ (Hirono et al. 2007b). Marked geochemical anomalies of fluid-mobile trace-element concentrations ( $\mathrm{Sr}, \mathrm{Cs}, \mathrm{Rb}$, and $\mathrm{Li}$ ) and of $\mathrm{Sr}$ isotope ratios in the fault gouge indicated that a high-temperature fluid at $\geq 350^{\circ} \mathrm{C}$ was present during the earthquake (Ishikawa et al. 2008). High magnetic susceptibility was also detected in the fault gouge by a nondestructive Multi-Sensor Core Logger (Hirono et al. 2006, 2007a), and thermomagnetic analyses showed that thermal decomposition 
of paramagnetic minerals caused magnetite formation at high temperature $\left(\geq 400^{\circ} \mathrm{C}\right)$ (Mishima et al. 2009).

However, these temperature determinations do not fully constrain the temperature reached in the fault zone during the earthquake. Both the fluid-mobile traceelement concentration and magnetic mineral analyses suggest a lower limit of frictional heating of $\geq 400^{\circ} \mathrm{C}$, but the upper limit has not yet been determined. The temperature of $868^{\circ} \mathrm{C}$ estimated from the reacted fraction resulting from the decarbonation reaction is probably not reliable because the low inorganic carbon content of the fault gouge might be caused not only by the reaction but also by the dissolution of carbonate minerals into pore fluid. Therefore, we focus hereon the irreversible maturation reaction of the carbonaceous material by heating. The reflectance of vitrinite, a primary component of coals and most sedimentary kerogens, is widely used as a geothermometer by petroleum and structural geologists. Vitrinite reflectance is sensitive to temperature and increases irreversibly when vitrinite is exposed to high temperature (e.g., Sweeney and Burnham 1990). Thus, it is highly sensitive to the maximum temperature as well as the temperature-time history. O'Hara et al. (2006), who conducted friction experiments with coal samples using velocities on the order of meters per second to simulate rapid heating during earthquake slip, showed that coal reflectance was increased even by a short heating duration. However, because their experiments were exposed to air causing the coal sample to react with oxygen, the increase could not be well correlated with the level of frictional heating. Kitamura et al. (2012) conducted similar experiments under oxygen-free, nitrogen atmosphere and confirmed that coal reflectance increased with rapid heating over short duration on the order of seconds.

In this study, we examined the reflectance of vitrinite retrieved from TCDP Hole B core samples and estimated the frictional heat generated during the Chi-Chi earthquake together with the values of several other parameters related to frictional heating. We also discuss the fault lubrication mechanism during the Chi-Chi earthquake.

\section{Methods}

The following subzones were encountered in FZB1136, from top to bottom (Figure 2): upper fracture-damaged zone $(1,134.40$ to $1,134.93 \mathrm{~m})$, upper breccia zone $(1,134.93$ to $1,136.22 \mathrm{~m})$, upper gray gouge zone $(1,136.22$ to $1,136.26 \mathrm{~m})$, black gouge zone $(1,136.26$ to $1,136.40 \mathrm{~m})$, lower gray gouge zone $(1,136.40$ to $1,136.46 \mathrm{~m})$, lower breccia zone $(1,136.46$ to $1,136.70 \mathrm{~m})$, and lower fracturedamaged zone (1,136.70 to $1,137.90 \mathrm{~m})$. The primary slip zone during the Chi-Chi earthquake was identified as a millimeter-thick shear zone within the black gouge at 1,136.38-m depth, because neoformed magnetite in the black gouge at that depth carries a stable paleomagnetic component consistent with the international geomagnetic reference field dipole magnetic vector (Chou et al. 2012).

We collected 16 subsamples from the FZB1136 core sample (Figure 2). Carbonaceous materials, including vitrinite grains, in the samples were first extracted by a CsF-HF technique (Cody et al. 2002; Cody and Alexander 2005; Alexander et al. 2007). The samples were treated with $2 \mathrm{~N} \mathrm{HCl}$ to remove metal, sulfide, and carbonate and then rinsed with milliQ water several times. After this rinsing, the samples were treated with two immiscible liquids, dioxane, and an aqueous CsF-HF solution (1.6 to $1.7 \mathrm{~g} \cdot \mathrm{ml}^{-1}$ and $\mathrm{pH} 5$ to 7 ). The carbonaceous materials liberated by this treatment were collected at the interface between the CsF-HF solution and the dioxane, rinsed in succession with $2 \mathrm{~N} \mathrm{HCl}, 1 \mathrm{~N}$ HCl-9 N HF, $2 \mathrm{~N} \mathrm{HCl}$, milliQ water, and methanol, dried at $40^{\circ} \mathrm{C}$ to $60^{\circ} \mathrm{C}$ for $12 \mathrm{~h}$, and finally mounted in synthetic resin. A surface of the resin including the carbonaceous materials was carefully polished for vitrinite reflectance measurements.

The vitrinite grains on the polished surface were identified under an oil immersion microscope, and the random reflectance $\left(R_{o}\right.$, as a percentage) was measured by using a microscope system with microspot lighting (critical illumination with a xenon lamp; spot size, $1.6 \mu \mathrm{m}$ ) and an avalanche photodiode module (Hamamatsu Photonics, C4777-01, Hamamatsu, Japan) to measure the intensity of the visible spectrum reflected (wavelength 546 $\pm 5 \mathrm{~nm}$ ). The reflectance was calibrated by using a series of mineral reflectance standards: $0.42 \%$ (spinel), $0.59 \%$ (leucosapphire), $0.92 \%$ (yttrium aluminum garnet), 1.73\% (gadolinium gallium garnet), and 7.5\% (silicon carbide), with an immersion oil with a refractive index of 1.518 . This procedure follows those outlined by the International Organization for Standardization (ISO) 7404-5 and the Japan Industrial Standards (JIS) M 8816.

To estimate the maximum attained temperature from the vitrinite reflectance, we used a kinetic model of vitrinite thermal maturation (Sweeney and Burnham 1990):

$$
R_{o}=e^{(-1.6+3.7 F)}
$$

where $F$ is the extent of the reaction (ranging from 0 to 0.85) controlled by a series of first-order Arrhenius kinetics (i.e., temperature-dependent reaction rates) that describe the parallel chemical reactions as follows:

$$
F=1-\sum_{i=1}^{n} f_{i}\left(w_{i} / w_{i, 0}\right)
$$

where $f_{i}$ is the stoichiometric coefficient for the $i$ th parallel reaction component, and $w_{i}$ and $w_{i, 0}$ are the reacted amount and the initial amount of the $i$ th component, 


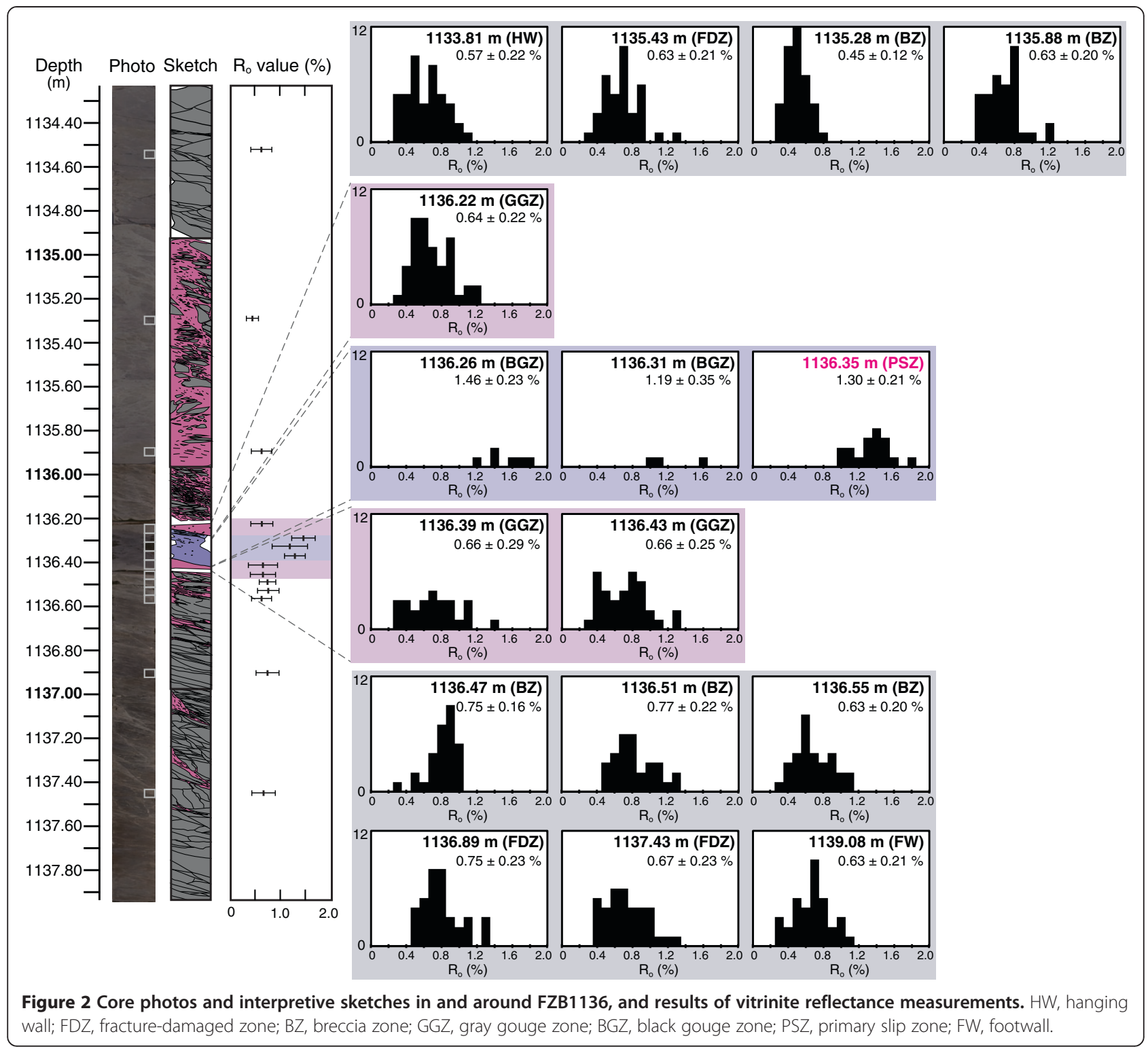

respectively (Sweeney and Burnham 1990). By combining Equations 1 and 2 and using the Arrhenius kinetics, the relationship among $R_{o}$, time $(t)$, and temperature $(T)$ can be expressed as:

$$
R_{o}=e^{2.1} \prod_{i=1}^{n} e^{-f_{i} e^{A t e^{-E_{i} / R T}}}
$$

where $A$ is the pre-exponential factor, $E_{i}$ is the activation energy of the $i$ th component, and $R$ is the gas constant (Polissar et al. 2011). This equation shows that a short exposure to high temperatures, such as during frictional heating by earthquake slip, can have a large effect on the evolution of $R_{o}$ and that $R_{o}$ is very sensitive to the total time spent near the peak temperature. Therefore, by using Equation 3 together with the parameter data presented by Sweeney and Burnham (1990), the peak temperature during past earthquakes can be estimated from the observed $R_{o}$ data. However, the temperature in a fault zone during slip changes with time in response to frictional heating and heat conduction. This change is expressed by applying a one-dimensional heat and thermal diffusion equation:

$$
\frac{\partial T}{\partial t}-\frac{\partial}{\partial x}\left(\kappa(T) \frac{\partial T}{\partial x}\right)-\frac{\partial}{\partial t}\left(\frac{\tau D}{w C_{p} \rho}\right)=0
$$

where $T$ is temperature, $t$ is time, $\kappa(T)$ is thermal diffusivity with temperature dependency, $x$ is the distance from the center of the slip zone $(x=0), \tau$ is shear stress, $D$ is slip distance, $w$ is slip-zone thickness, $C_{p}$ is specific heat capacity, and $\rho$ is density. For simplicity, convective 
heat transfer and dynamic fault weakening are ignored. For the black gouge, $\rho=2,200 \mathrm{~kg} \cdot \mathrm{m}^{-3}$ (Hirono et al. 2006) and $T_{O}=46.5^{\circ} \mathrm{C}$ (Kano et al. 2006). The $C_{p}$ value of Chinshui shale, which is the host rock of the Chelungpu fault, has been determined to be approximately $1,300 \mathrm{~J} \cdot \mathrm{kg}^{-1} \cdot \mathrm{K}^{-1}$, and the $\kappa$ value can be expressed by $\kappa=2.27 \times 10^{-4} T^{-1}+1.78 \times 10^{-7} \mathrm{~m}^{2} \cdot \mathrm{s}^{-1}$ for $T<573^{\circ} \mathrm{C}$ and $\kappa=4.73 \times 10^{-7} \mathrm{~m}^{2} \cdot \mathrm{s}^{-1}$ for $T \geq 573^{\circ} \mathrm{C}$ (Hirono and Hamada 2010). In the primary slip zone of the Chi-Chi earthquake, $w=5 \mathrm{~mm}$ (Chou et al. 2012), the risetime was $6 \mathrm{~s}$, and the total slip distance was $8.3 \mathrm{~m}$ (Ma et al. 2006). Thus, by adopting the finite difference method to solve Equations 3 and 4 simultaneously, values of peak temperature and $\tau$ consistent with the measured values of $R_{o}$ can be determined. The time increment used in the calculations was $0.01 \mathrm{~s}$, the grid size was $0.5 \mathrm{~mm}$, and the boundary condition was $T=46.5^{\circ} \mathrm{C}$ at $x>200 \mathrm{~mm}$.

\section{Results and discussion}

Histograms of the vitrinite reflectance data for all samples and the average $R_{o}$ values with their standard deviations in relation to sample depth are shown in Figure 2. In the hanging wall, the average $R_{o}$ values of the host and fracture-damaged rocks ranged from $0.45 \%$ to $0.63 \%$. The average $R_{o}$ value of the upper gray gouge sample adjacent to the black gouge was $0.64 \%$, which is almost the same as the values of the upper rocks. The average $R_{o}$ value of the lower gray gouge samples was $0.66 \%$, and those of the samples from the breccia zone, fracture-damaged zone, and host rock were $0.63 \%$ to $0.77 \%$. However, the $R_{o}$ values of the black gouge samples were markedly high at $1.19 \%$ to $1.46 \%$, and the average $R_{o}$ value in the primary slip zone was $1.30 \% \pm 0.21 \%$.

By numerically solving the simultaneous Equations 3 and 4 with in-situ ambient temperature of $46.5^{\circ} \mathrm{C}$ (Kano et al. 2006) and initial $R_{o}$ value of 0.65 (the average value of the surrounding samples), the $\tau$ value for the primary slip zone was determined $1.00 \pm 0.04 \mathrm{MPa}$, and the temperature profile (peak temperature, $626^{\circ} \mathrm{C}$ ) and the evolution of the $R_{o}$ value at the center of the slip zone were obtained (Figure 3). On the other hand, the $R_{o}$ values of the hanging wall samples and those of the footwall samples were calculated to be $99^{\circ} \mathrm{C}$ to $128^{\circ} \mathrm{C}$ and $128^{\circ} \mathrm{C}$ to $151^{\circ} \mathrm{C}$, respectively, by assuming a heat duration of 2 million years, which are probably associated with the burial history of the Chinshui shale. These maximum temperatures recorded in the surrounding rocks agree well with the value of $130^{\circ} \mathrm{C}$ in the host rocks nearby a different shallow $(330 \mathrm{~m})$ fault core sample (Sakaguchi et al. 2007).

We calculated the friction coefficient from the $\tau$ value in the primary slip zone associated with the 1999 Chi-Chi earthquake (Ma et al. 2006; Chou et al. 2012). The effective vertical stress around sample FZB1136 was
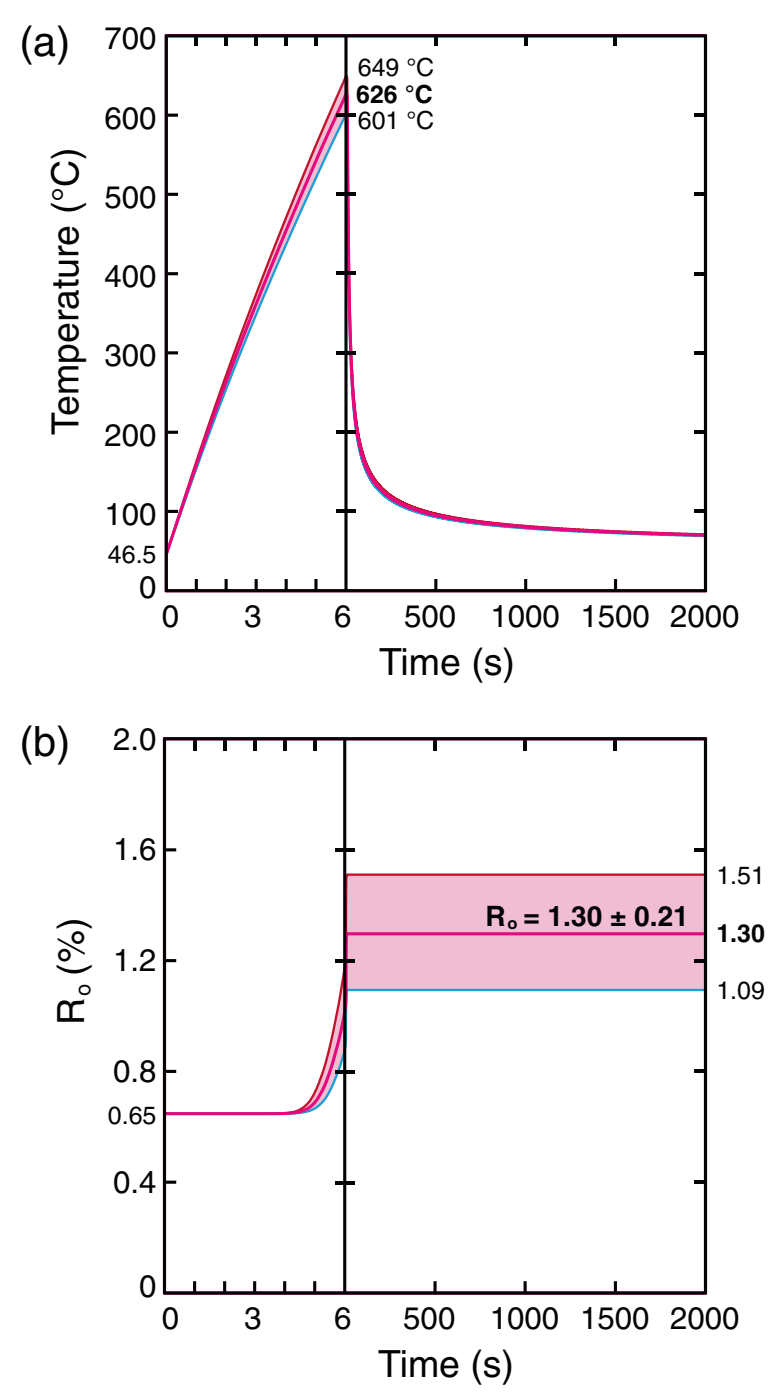

Figure 3 Temperature-time profile in primary slip zone during Chi-Chi earthquake (a) and evolution of vitrinite reflectance (b). Temperature-time profile is reconstructed for $R_{o}=1.30 \% \pm 0.21 \%$ (pink curve, $R_{0}=1.30$; blue curve, $R_{0}=1.09$; red curve, $R_{0}=1.51$; light pink shading, their $R_{0}$ range). (b) The vitrinite reflectance has evolved with time in the primary slip zone during the Chi-Chi earthquake.

17.8 $\mathrm{MPa}$ (rock density, 2,600 $\mathrm{kg} \cdot \mathrm{m}^{-3}$ ) by assuming hydrostatic pore-fluid pressures, and the dip of the fault plane was $35^{\circ}$ (Hirono et al. 2007a). Assuming that the stress normal to the fault $\left(\sigma_{n}\right)$ was equal to that of the static state, and that the horizontal stress $\left(\sigma_{H}\right)$ was equal to the vertical stress $\left(\sigma_{V}\right)$, the stress normal to the fault was $17.8 \mathrm{MPa}$, which gives an apparent friction coefficient of 0.06. For a thrust fault, maximum $\sigma_{H}$ is higher than $\sigma_{V}$ (Sibson 1974). Assuming that $\sigma_{n}$ is equal to the static stress state and that maximum $\sigma_{H}$ is twice as high as $\sigma_{V}$, then $\sigma_{n}$ is $43.7 \mathrm{MPa}$, which gives an apparent friction coefficient of 0.02 .

However, Kitamura et al. (2012) attributed the maturation of coal by friction experiments not only to high 
temperature but also to mechanochemically enhanced reaction kinetics and flash heating at asperity contacts, suggesting that the fault temperature estimated from vitrinite reflectance might be overestimated. Thus, our estimated temperature, $626^{\circ} \mathrm{C}$, should be considered an upper limit. The lower limit has been already constrained to $400^{\circ} \mathrm{C}$ by both fluid-mobile trace-element concentration and magnetic mineral analyses (Ishikawa et al. 2008; Mishima et al. 2009). Therefore, we infer that the peak temperature during the Chi-Chi earthquake was $400^{\circ} \mathrm{C}$ to $626^{\circ} \mathrm{C}$, corresponding to an apparent friction coefficient of 0.03 to 0.06 for the $\sigma_{H}=\sigma_{V}$ stress state and 0.01 to 0.02 for the $\sigma_{H}=2 \sigma_{V}$ state. These values are markedly low compared to the initial and residual friction coefficients of 0.736 and of 0.173 , respectively, of gouge samples from FZB1136 measured during a highvelocity frictional test carried out by Tanikawa et al. (2007).

Such low friction coefficients $(\leq 0.06)$ at all the cases in this study agree well with seismological observations of low levels of high-frequency radiation, fast slip velocities, and high slip displacement, all of which indicate a low level of friction on the fault (e.g., Ma et al. 2003). They are also consistent with the residual heat anomaly of $0.06^{\circ} \mathrm{C}$, which corresponds to an apparent friction coefficient of 0.04 to 0.08 , obtained by borehole temperature measurement in TCDP Hole A (Kano et al. 2006). In addition, anomalous concentrations of fluid-mobile elements and $\mathrm{Sr}$ isotope ratios resulting from the interaction of minerals with high-temperature $\left(\geq 350^{\circ} \mathrm{C}\right)$ fluids have been reported (Ishikawa et al. 2008). Taking into consideration these results, thermal pressurization may have occurred along the northern Chelungpu fault during the Chi-Chi earthquake.

We note again the need to improve the accuracy of vitrinite temperature estimation. Kitamura et al. (2012) confirmed that the commonly used kinetic model of Sweeney and Burnham (1990) for vitrinite reflectance does not yield accurate estimates of the peak temperature in a fault zone resulting from fast frictional heating rates. Shear deformation mechanochemically may induce a change in the molecular structure of organic matter (e.g., Fulton and Harris 2012). Because of not only such rapid heating and mechanochemical effects but also the types of carbonaceous components present, the kinetics may be different from that of Sweeney and Burnham (1990). On the other hand, the estimation of the shear stress and the resultant calculations of the friction coefficient also include some uncertainties: the state and magnitude of stress during seismic rupture might not be the same as the static values, and dynamic changes of the friction coefficient and stress drop are not considered. For more accurate estimation, further experimental work on vitrinite reflectance kinetics and advanced modeling taking into consideration changes of the dynamic parameters hold promise for constraining further slip parameters such as dynamic shear stress and peak temperature during large earthquakes. In addition, for comprehensive understanding of the mineral and chemical changes that occur in the slip zone during an earthquake and how they influence the slip behavior, a complete data set of experienced temperature, obtained by multiple approaches using various proxies, is required.

\section{Conclusions}

Using the thermal kinetics of vitrinite maturation of Sweeney and Burnham (1990) together with the thermal model of frictional heat generation and diffusion, we determined that during the 1999 Chi-Chi earthquake, the peak temperature and apparent friction coefficient in the primary slip zone were $626^{\circ} \mathrm{C}$ and 0.02 to 0.06 , respectively. However, taking into consideration the probable overestimation of the temperature and other constraints indicating a temperature $\geq 400^{\circ} \mathrm{C}$, we concluded that the peak temperature was $400^{\circ} \mathrm{C}$ to $626^{\circ} \mathrm{C}$, corresponding to an apparent friction coefficient of 0.01 to 0.06. Thus, such low apparent friction coefficient and the previous evidence of a high-temperature fluid suggest that thermal pressurization likely contributed to dynamically weakening the fault during the Chi-Chi earthquake.

\section{Competing interests}

The authors declare that they have no competing interests.

\section{Authors' contributions}

YM prepared the samples, carried out the vitrinite reflectance measurements, and performed the numerical simulation to determine the slip parameters during the 1999 Chi-Chi earthquake. TH designed this study and drafted the manuscript. HY supported the extraction of carbonaceous materials technically. HM and MK participated in the vitrinite reflectance measurements. MI, WT, and TI helped to draft the manuscript. All authors read and approved the final manuscript.

\section{Acknowledgements}

We thank Sheng-Rong Song for giving us the opportunity to analyze samples from TCDP Hole B. We also thank P. M. Fulton and an anonymous reviewer for their constructive reviews, and editor $C$. Rowe for editing this paper. This study was supported by a Japan Ministry of Education, Culture, Sports, Science and Technology Grant-in-Aid for Young Scientists (A) 23684039, 2013

\section{Author details}

${ }^{1}$ Department of Earth and Space Science, Graduate School of Science, Osaka University, Toyonaka, Japan. ${ }^{2}$ Faculty of Education and Integrated Arts and Sciences, Waseda University, Tokyo, Japan. ${ }^{3}$ Department of Earth and Planetary Systems Science, Graduate School of Science, Hiroshima University, Higashi-Hiroshima, Japan. ${ }^{4}$ Center for Advanced Marine Core Research, Kochi University, Nankoku, Japan. ${ }^{5}$ Kochi Institute for Core Sample Research, Japan Agency for Marine-Earth Science and Technology, Nankoku, Japan.

Received: 19 November 2013 Accepted: 17 April 2014

Published: 1 May 2014

\section{References}

Alexander CMOD, Fogel M, Yabuta H, Cody GD (2007) The origin and evolution of chondrites recorded in the elemental and isotopic compositions of their macromolecular organic matter. Geochim Cosmochim Acta 71:4380-4403 
Andrews DJ (2005) Thermal pressurization explains enhanced long-period motion in the Chi-Chi earthquake. Eos Trans AGU Fall Meet Suppl Abstract 86(52):S34A-04

Chou YM, Song SR, Aubourg C, Lee TQ, Boullier AM, Song YF, Yeh EC, Kuo LW, Wang CY (2012) An earthquake slip zone is a magnetic recorder. Geology 40:551-554, doi:10.1130/G32864.1

Cody GD, Alexander CMOD (2005) NMR studies of chemical structural variation of insoluble organic matter from different carbonaceous chondrite groups. Geochim Cosmochim Acta 69:1085-1097

Cody GD, Alexander CMOD, Tera F (2002) Solid-state $\left({ }^{1} \mathrm{H}\right.$ and $\left.{ }^{13} \mathrm{C}\right)$ nuclear magnetic resonance spectroscopy of insoluble organic residue in the Murchison meteorite: a self-consistent quantitative analysis. Geochim Cosmochim Acta 66:1851-1865

Fulton PM, Harris RN (2012) Thermal considerations in inferring frictional heating from vitrinite reflectance and implications for shallow coseismic slip within the Nankai Subduction Zone. Earth Planet Sci Lett 335-336:206-215, doi:10.1016/j.epsl.2012.04.012

Hirono T, Hamada Y (2010) Specific heat capacity and thermal diffusivity and their temperature dependencies in a rock sample from adjacent to the Taiwan Chelungpu fault. J Geophys Res 115:B05313, doi:10.1029/ 2009JB006816

Hirono T, Lin W, Yeh E, Soh W, Hashimoto Y, Sone H, Matsubayashi O, Aoike K, Ito H, Kinoshita M, Murayama M, Song S, Ma K, Hung J, Wang C, Tsai Y (2006) High magnetic susceptibility of fault gouge within Taiwan Chelungpu fault: nondestructive continuous measurements of physical and chemical properties in fault rocks recovered from Hole B, TCDP. Geophys Res Lett 33:L15303, doi:10.1029/2006GL026133

Hirono T, Yeh E, Lin W, Sone H, Mishima T, Soh W, Hashimoto Y, Matsubayashi O, Aoike K, Ito H, Kinoshita M, Murayama M, Song S, Ma K, Hung J, Wang C, Tsai Y, Kondo T, Nishimura M, Moriya S, Tanaka T, Fujiki T, Maeda L, Muraki H, Kuramoto T, Sugiyama K, Sugawara T (2007a) Nondestructive continuous physical property measurements of core samples recovered from Hole B, Taiwan Chelungpu-fault Drilling Project. J Geophys Res 112:B07404, doi:10.1029/2006JB004738

Hirono T, Yokoyama T, Hamada Y, Tanikawa W, Mishima T, Ikehara M, Famin V, Tanimizu M, Lin W, Soh W, Song S (2007b) A chemical kinetic approach to estimate dynamic shear stress during the 1999 Taiwan Chi-Chi earthquake. Geophys Res Lett 34:L19308, doi:10.1029/2007GL030743

Hirono T, Sakaguchi M, Otsuki K, Sone H, Fujimoto K, Mishima T, Lin W, Tanikawa W, Tanimizu M, Soh W, Yeh E, Song S (2008) Characterization of slip zone associated with the 1999 Taiwan Chi-Chi earthquake: X-ray CT image analyses and microstructural observations of the Taiwan Chelungpu fault. Tectonophysics 449:63-84

Ikehara M, Hirono T, Tadai O, Sakaguchi M, Kikuta H, Fukuchi T, Mishima T, Nakamura N, Aoike K, Fujimoto K, Hashimoto Y, Ishikawa T, Ito H, Kinoshita M, Lin W, Masuda K, Matsubara T, Matsubayashi O, Mizoguchi K, Murayama M, Otsuki K, Sone H, Takahashi M, Tanikawa W, Tanimizu M, Soh W, Song S (2007) Low total and inorganic carbon contents within the Chelungpu fault. Geochem J 41:391-396

Ishikawa T, Tanimizu M, Nagaishi K, Matsuoka J, Tadai O, Sakaguchi M, Hirono T, Mishima T, Tanikawa W, Lin W, Kikuta H, Soh W, Song S (2008) Coseismic fluid-rock interactions at high temperatures in the Chelungpu fault. Nat Geosci 1:679-683

Kano Y, Mori J, Fujio R, Ito H, Yanagidani T, Nakao S, Ma K (2006) Heat signature on the Chelungpu fault associated with the 1999 Chi-Chi Taiwan earthquake. Geophys Res Lett 33:L14306, doi:10.1029/2006GL026733

Kitamura M, Mukoyoshi H, Fulton PM, Hirose T (2012) Coal maturation by frictional heat during rapid fault slip. Geophys Res Lett 39:L16302, doi:10.1029/2012GL052316

Lin W, Yeh EC, Ito H, Hung JH, Hirono T, Soh W, Ma KF, Kinoshita M, Wang CY, Song SR (2007) Current stress state and principal stress rotations in the vicinity of the Chelungpu fault induced by the 1999 Chi-Chi Taiwan earthquake. Geophys Res Lett 34:L16307, doi:10.1029/2007GL030515

Ma KF, Brodsky EE, Mori J, Song TA, Kanamori H (2003) Evidence for fault lubrication during the 1999 Chi-Chi Taiwan earthquake (Mw7.6). Geophys Re Lett 30(5):1244, doi:10.1029/2002GL015380

Ma KF, Tanaka H, Song S, Wang C, Hung J, Song Y, Yeh E, Soh W, Sone H, Kuo L, Wu H (2006) Slip zone and energetics of a large earthquake from the Taiwan Chelungpu-fault Drilling Project. Nature 444:473-476
Mishima T, Hirono T, Nakamura N, Tanikawa W, Soh W, Song S (2009) Changes to magnetic minerals caused by frictional heating during the 1999 Taiwan Chi-Chi earthquake. Earth Planets Space 61:797-801

O'Hara K, Mizoguchi K, Shimamoto T, Hower JC (2006) Experimental frictional heating of coal gouge at seismic slip rate: evidence for devolatilization and thermal pressurization of gouge fluids. Tectonophysics 424:109-118, doi:10.1016/j.tecto.2006.07.007

Polissar PJ, Savage HM, Brodsky EE (2011) Extractable organic material in fault zones as a tool to investigate frictional stress. Earth Planet Sci Lett 311(3-4):439-447, doi.org/10.1016/j.epsl.2011.09.004

Sakaguchi A, Yanagihara A, Ujiie K, Tanaka H, Kameyama M (2007) Thermal maturity of a fold-thrust belt based on vitrinite reflectance analysis in the Western Foothills complex, western Taiwan. Tectonophysics 443(3-4):220-232, doi:10.1016/j.tecto.2007.01.017

Shin T, Teng T (2001) An overview of the 1999 Chi-Chi Taiwan Earthquake. Bull Seism Soc Am 91:895-913

Sibson RH (1974) Frictional constraints on thrust, wrench and normal faults. Nature 249:542-544

Sweeney JJ, Burnham AK (1990) Evaluation of a simple model of vitrinite reflectance based on chemical kinetics. AAPG Bull 74:1559-1570, doi:10.1306/0C9B251F-1710-11D7-8645000102C1865D

Tanikawa W, Mishima T, Hirono T, Lin W, Shimamoto T, Soh W, Song SR (2007) High magnetic susceptibility produced in high-velocity frictional tests on core samples from the Chelungpu fault in Taiwan. Geophys Res Lett 34:L15304, doi:10.1029/2007GL030783

Wu H, Ma K, Zoback M, Boness N, Ito H, Hung J, Hickman S (2007) Stress orientations of Taiwan Chelungpu-Fault Drilling Project (TCDP) hole-A as observed from geophysical logs. Geophys Res Lett 34:L01303, doi:10.1029/ 2006GL028050

\section{doi:10.1186/1880-5981-66-28}

Cite this article as: Maekawa et al:: Estimation of slip parameters associated with frictional heating during the 1999 Taiwan

Chi-Chi earthquake by vitrinite reflectance geothermometry. Earth,

Planets and Space 2014 66:28.

\section{Submit your manuscript to a SpringerOpen ${ }^{\odot}$ journal and benefit from:}

- Convenient online submission

- Rigorous peer review

- Immediate publication on acceptance

- Open access: articles freely available online

- High visibility within the field

- Retaining the copyright to your article

Submit your next manuscript at $>$ springeropen.com 